the redundancy, the safety and the training that the soldiers are going to get, the risk is negligible if not minimal."

In adopting laser dazzlers, the military hopes to reduce the number of incidents in which Canadian troops fire on innocent civilians who don't understand warnings to stop, says Dufour.

But as Anthony Salloum, the program director at the Rideau Institute, a nonprofit research, advocacy and consulting group points out, the fact dazzlers work well under controlled testing circumstances does not necessarily mean they'll translate easily into the field. "They're being controlled [by soldiers] in a theatre of war, where you can't control the conditions, or whether a target is 500 feet away from you or 10 feet away from you," he says. "It holds the potential to do permanent damage to people.'

Salloum is also concerned that a soldier handling the laser dazzler will be injured or thrown the wrong way and accidentally aim the device at a comrade.

"Another risk of employing the NLLDs [Non-Lethal Laser Dazzler] comes from the possibility of an accidental activation of the device, potentially exposing soldiers within the NOHD [Nominal Ocular Hazard Distance] to a hazardous level of radiation," the safety statement warns. It recommends training programs to mitigate that risk.
The Canadian Forces has a good training program and is equipping its soldiers with protective eyewear, says Eagan.

The United States is already using similar, but more powerful laser dazzlers in Iraq to warn and disorient people, and has trained the Iraqi population to stop or pull their vehicles over to the side of the road when they see the green light, says Dufour.

These devices are simply another tool in the Canadian Forces' arsenal, to help sort out innocent civilians from people who represent a threat, says Eagan. Laura Eggertson, CMAJ

DOI:10.1503/cmaj.090531

\title{
Asbestos panel chair mystified by secrecy surrounding report
}

Published at www.cmaj.ca on Apr.14. Updated May 4.

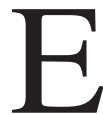
xposure to chrysotile asbestos has a strong relationship with lung cancer and some connection to other forms of cancer, according to reports written by a Health Canada-commissioned expert panel and released this spring.

The panel's conclusions essentially supported previous studies, and Chair Trevor Ogden is surprised that the government delayed the release of the reports for more than a year.

"Many people who read the reports will wonder what all the fuss is about," Ogden, editor-in-chief of the Annals of Occupational Hygiene, says in an email to CMAJ. "If they had been put on the Health Canada website a year ago they would have attracted little interest. This is a classic example of a document gaining disproportionate status by being kept secret."

Health Canada, however, claims the delay was necessary. In an email to CMAJ, Health Canada Media Relations Officer Christelle Legault says, "Health Canada took the time necessary to carefully review the findings of the report, and to consult other federal and provincial partners."

The 6-member expert panel met in

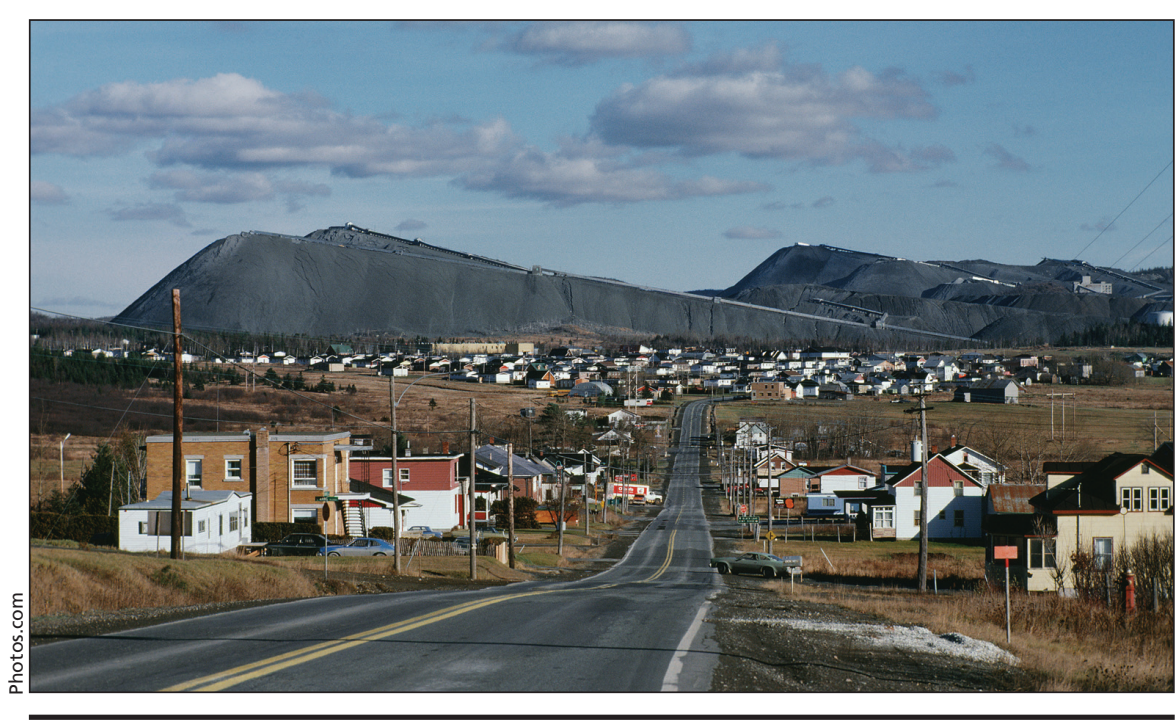

A special Health Canada panel concurred with 2 major epidemiological reviews that there is a link between chrysotile asbestos exposure and cancer. Those studies found that there was less disease than expected among people in the Quebec chrysotile mining industry but higher than expected among those involved in South Carolina textile manufacturing.

Montréal, Quebec, on Nov. 13-14, 2007 , to discuss the relationship between exposure to chrysotile asbestos and lung cancer, pleural mesothelioma and peritoneal mesothelioma. On Mar. 18, 2008, Ogden submitted 2 reports Summary Proceedings of the Panel Meetings and Consensus Statement and Summary — to Karen Lloyd, acting director general of the Safe Environments Programme at Health Canada's Healthy
Environments and Consumer Safety Branch.

In a letter accompanying the reports, Ogden wrote: "The Panel supported the approach of 2 major reviews, which give information on the relationship of the cancers to chrysotile exposure. Generally these show a strong relationship of exposure with lung cancer, but a much less certain relationship with mesothelioma."

In October 2008, Ogden voiced con- 
cerns about the delay of the reports' release, claiming the Canadian government was disguising economic and political concerns as scientific decisions (CMAJ 2008;179[9]:886-7). The reports were released in response to a 4-monthold Access to Information request by Amir Attaran, Canada Research Chair in Law, Population Health and Global Development Policy at the University of Ottawa, and CMAJ Associate Editor, Editorials.

Canada is the fifth-largest exporter of chrysotile asbestos in the world. In 2006, Canada was the sole Western nation to oppose adding the substance to a list of hazardous chemicals under the United Nations' Rotterdam Convention.

In October 2008, when the 126 parties to the convention met again, in Rome, Italy, Canadian representatives abstained from discussions but were still blamed by some for the failure to add chrysotile asbestos to the list, which would require countries importing it to give "prior informed consent" that they were aware the substance is hazardous (CMAJ 2008;179[12]:1257).

The debate surrounding chrysotile asbestos revolves around whether it is as carcinogenic as amphibole asbestos, a form of the substance that differs chemically.

According to the consensus statement, the panelists did not reach absolute agreement on the questions they were asked to address, but Ogden says they agreed on the biggest issue. In an email, he writes: "I think that [no one] questioned in the 2 days of discussions that exposure to commercial chrysotile asbestos causes cancer. The disagreement was on the degree of risk, especially at low exposure."

All 6 panelists signed the consensus statement, though 2 wrote accompanying statements of reservation - one claiming the consensus statement underestimated the risk of exposure to chrysotile asbestos, the other claiming it overestimated the risk.

Other concerns raised included whether "chrysotile can be realistically distinguished from amphiboles in risk of lung cancer ... the unexplained and apparently much higher carcinogenicity of chrysotile in one textile plant ... the likelihood that risk may not be de- tectable at modern Canadian exposure levels."

Alex Burdorf, a member of a Dutch Health Council committee responsible for setting standards on asbestos use, says that the effects of asbestos on health are well documented in the field of occupational health.

Because there is so much information available on the topic, Burdorf says, systematic reviews of existing literature are essential to evaluate the differences in carcinogenicity of different fibre types. He says the expert panel's report, however, doesn't present any novel conclusions.

"In fact, it again opens the door for the historical debate [about] whether chrysotile can cause mesothelioma or not," Burdorf, a professor of public health at Erasmus University in the Netherlands, writes in a statement to CMAJ. "This is a setback, given the stringent legislation in most western countries. We can only hope that the mesothelioma statement will not be deliberately misused."

Paul Demers, director of the School of Environmental Health at the University of British Columbia in Vancouver, British Columbia, says he isn't surprised that the expert panel didn't reach a clear consensus.

"They designed it to get the maximal range of opinions out there," he says. "It doesn't surprise me, considering who was on the committee, that they didn't come to an agreement."

Still, he says, it was a useful exercise and the government did a disservice to science by holding onto the report for so long. "There is no logical reason to suppress the report."

In a statement that he posted on various email lists, Ogden expressed praise for Health Canada's decision to convene the expert panel, but scorn for the federal government's secrecy: "It was far-sighted of Health Canada to bring together disparate experts in this way but that department's vision has been spoilt by the wider government's suppression of the reports for over a year."

The report can be requested from Health Canada by contacting panel@hcsc.gc.ca. — Roger Collier, CMAJ

DOI:10.1503/cmaj.090728 